Article

\title{
New BEDT-TTF Radical Cation Salt with Mixed Anions: $\alpha^{\prime}$-[BEDT-TTF $]_{2}\left[\mathrm{CuBr}_{2}\right]_{0.4}\left[\mathrm{CuCl}_{2}\right]_{0.6}$
}

\author{
Kazuya Kubo $^{1,2, *}$ and Masahiro Yamashita ${ }^{2}$
}

1 Research Institute for Electronic Science, Hokkaido University, Sapporo 001-0020, Japan

2 Department of Chemistry, Graduate School of Science Tohoku University, 6-3 Aramaki-Aza-Aoba, Aoba-ku, Sendai, 980-8578, Japan; E-Mail: yamasita@agnus.chem.tohoku.ac.jp

* Author to whom correspondence should be addressed; E-Mail: kkubo@es.hokudai.ac.jp;

Tel.: +81-11-706-9418; Fax: +81-11-706-9420.

Received: 8 March 2012; in revised form: 13 April 2012 / Accepted: 13 April 2012 /

Published: 23 April 2012

\begin{abstract}
A new mixed-anion crystal composed of BEDT-TTF radical cation salt [BEDT-TTF $]_{2}\left(\mathrm{CuBr}_{2}\right)_{0.4}\left(\mathrm{CuCl}_{2}\right)_{0.6}$ with an $\alpha$-type donor arrangement with a formal charge of +0.5 per BEDT-TTF was prepared by using a chemical oxidation method and characterized by using X-ray diffraction, four-probe electrical resistivity measurements (semiconductor: $\rho_{\mathrm{rt}}=2 \times 10^{2} \Omega \mathrm{cm}, E_{\mathrm{a}}=0.2 \mathrm{eV}$ ), and energy band calculations. The results showed that this system had a quasi-one dimensional Fermi surface.
\end{abstract}

Keywords: molecular conductor; mixed crystal; BEDT-TTF; quasi-one dimensional character; $\alpha$-type donor arrangement; Mott-Hubbard insulator

\section{Introduction}

The organic donor molecule BEDT-TTF (bis(ethylenedithio)tetrathiafulvalene) can be used to prepare a series of charge transfer salts with a wide range of electronic properties [1]. The electronic properties of the salts are caused by various crystalline modifications, such as $\alpha_{-}, \alpha^{\prime}-, \alpha^{\prime \prime}-, \theta-, \kappa^{-}, \beta-$, $\beta^{\prime}$-, and $\beta^{\prime \prime}$-types, which exhibit the transport properties of semiconductors, metals, or even superconductors in relation to their structures and often undergo electronically and structurally reversible phase transitions in relation to pressure and/or temperature [2-4]. The electronic properties of the BEDT-TTF layers in these crystals depend dramatically on the sulfur-sulfur overlaps of neighboring BEDT-TTF molecules, which can also be changed by anion substitution or possibly by 
order-disorder transformations of the ethylene groups of the BEDT-TTF molecule. The organic conductor $\kappa$-[BEDT-TTF $]_{2}\left(\mathrm{Cu}\left(\mathrm{N}(\mathrm{CN})_{2}\right) \mathrm{Cl}_{1-x} \mathrm{Br}_{x}\right.$ exhibits superconductivity under hydrostatic pressure. The critical pressure for the occurrence of superconductivity $\left(P_{\text {crit }}=0.029 \mathrm{GPa}\right.$ for $\left.x=0\right)$ is lowered by increasing $\mathrm{Br}^{-}$content $[5,6]$. The metal-insulator transition temperature for $\theta$-[BEDT-TTF] $]_{2}\left(\mathrm{Rb}_{1-x} \mathrm{Cs}_{x}\right) \mathrm{Zn}(\mathrm{SCN})_{4}$ depends on the ratio of $\mathrm{Rb}$ and $\mathrm{Cs}$ [7]. The radical cation salt with mixed anions $\theta$-[BEDT-TTF $]_{2}\left(\mathrm{I}_{3}\right)_{1-x}(\mathrm{~A})_{x}$ $\left(\mathrm{A}=\mathrm{AuI}_{2}{ }^{-}\right.$and $\mathrm{I}_{2} \mathrm{Br}$ ) exhibits partial superconducting behavior [8]. Thus, the shapes and sizes of anions in the BEDT-TTF salts affect their physical properties.

The charge transfer salts $\alpha^{\prime}-[\mathrm{BEDT}-\mathrm{TTF}]_{2} X\left(X=\mathrm{PF}_{6}{ }^{-}, \mathrm{ClO}_{4}{ }^{-}, \mathrm{AuBr}_{2}{ }^{-}, \mathrm{Ag}(\mathrm{CN})_{2}{ }^{-}, \mathrm{CuCl}_{2}{ }^{-}, \mathrm{C}_{4}(\mathrm{CN})_{6}^{-}\right.$, $\mathrm{CH}_{3} \mathrm{C}_{6} \mathrm{H}_{4} \mathrm{SO}_{3}{ }^{-}, \mathrm{C}_{5} \mathrm{CN}_{5}{ }^{-}$, and $\left.\mathrm{N}\left(\mathrm{CN}_{2}\right)^{-}\right)$are Mott-Hubbard insulators due to twisted dimer units of the donors which repeat along the stacking axis (the $a$ axis) [9-11]. Mott-Hubbard insulators can exhibit different electronic properties upon application of physical or chemical pressures. In other words, the transfer integrals $(t)$ between the donors and the bandwidth $(W)$, respectively, change. For example, $\kappa$-[BEDT-TTF $]_{2}\left(\mathrm{Cu}\left(\mathrm{N}(\mathrm{CN})_{2}\right) \mathrm{Cl}\right)$ is a Mott-Hubbard type insulator, which becomes a superconductor upon application of hydrostatic pressure $(>0.03 \mathrm{GPa})$ or by exchanging the $\mathrm{Cl}^{-}$ion with a $\mathrm{Br}^{-}$ion $[5,6]$. In this work, we focused on new BEDT-TTF radical cation salt formed by $\alpha$-arrangement of the donor molecule with mixed anions, and prepared $\alpha^{\prime}$-[BEDT-TTF] $]_{2}\left(\mathrm{CuBr}_{2}\right)_{0.4}\left(\mathrm{CuCl}_{2}\right)_{0.6}(\mathbf{1})$, in order to control $W$ and $t$. To our knowledge, this salt is the first example of an $\alpha^{\prime}$-type BEDT-TTF salt with mixed anions. In this paper, we report the crystal structure and electronic state of the mixed-anion crystal.

\section{Results and Discussion}

\subsection{Preparation}

Black plate-like single crystals of $\mathbf{1}$ were obtained by oxidation of neutral BEDT-TTF using a $\mathrm{MeOH}$ solution of a mixture of $\mathrm{CuBr}_{2}$ and $\mathrm{CuCl}_{2}$ as oxidants at room temperature, during which $\mathrm{Cu}$ (II) ions are reduced to $\mathrm{Cu}(\mathrm{I})$ ions (see next section). Electrochemical crystallization to prepare (TBA)Cu(I) $X_{2}\left(\mathrm{TBA}^{+}=\right.$tetrabutylammonium cation; $X=\mathrm{Br}^{-}$or $\left.\mathrm{Cl}^{-}\right)$, according to the literature method for preparation of $\alpha^{\prime}-[\mathrm{BEDT}-\mathrm{TTF}]_{2}\left(\mathrm{CuCl}_{2}\right)$ [11], was tried. However, the desired salt was not obtained. Although the main product of the electrochemical oxidation method was single crystals of $\alpha^{\prime}$-[BEDT-TTF $]_{2}\left(\mathrm{CuCl}_{2}\right)$, our preparation method is easier for obtaining a mixed crystal. The concentration ratio between the oxidants is important to obtain the mixed crystal. We tried to prepare the salt by using various ratios in order to improve the quality of the salt and found that if the amount of $\mathrm{CuBr}_{2}$ was higher, for example, $\mathrm{CuBr}_{2}: \mathrm{CuCl}_{2}=9: 1$, low quality crystals formed. X-ray quality crystals of other salts could not be prepared by these methods. Furthermore, the title compound and salts with other anionic ratios were not obtained by changing the ratios of the donor and the oxidants. Thus, although the yield of $\mathbf{1}$ was very low, the reaction ratio between the oxidants is better.

\subsection{Molecular Structure of Cation and Anion Moieties of $\mathbf{1}$}

Crystallographic data for $\mathbf{1}$ are summarized in Table 1 . In the crystal, the asymmetric unit is composed of one cation and half of an anion, $\left[\mathrm{CuX}_{2}\right]^{-}(X=\mathrm{Br}$ or $\mathrm{Cl})$. $\mathrm{A} \mathrm{Cu}$ ion of the linear anion is located on an inversion center. Figure 1 shows the molecular structure of the cation moiety in the salt with the atom-labeling scheme. Disorder was observed in one of terminal ethylene groups of the donor 
molecules. Selected bond lengths and angles are summarized in Table 2. The bond lengths and angles are similar to those of other 2:1 cation radical salts composed of BEDT-TTF $[1-8,10,11]$.

Table 1. Crystallographic data for $\mathbf{1 .}$

\begin{tabular}{|c|c|}
\hline Formula & $\mathrm{C}_{20} \mathrm{H}_{16} \mathrm{Br}_{0.8} \mathrm{Cl}_{1.2} \mathrm{CuS}_{16}$ \\
\hline Formula weight & 938.85 \\
\hline Crystal size (mm) & $0.16 \times 0.16 \times 0.02$ \\
\hline Crystal system & monoclinic \\
\hline Space group & $P 2 / \mathrm{c}$ \\
\hline$a(\AA)$ & $7.8124(14)$ \\
\hline$b(\AA)$ & $6.6564(11)$ \\
\hline$c(\AA)$ & $30.444(6)$ \\
\hline$\beta\left({ }^{\circ}\right)$ & $96.062(2)$ \\
\hline$V\left(\AA^{3}\right)$ & $1574.3(5)$ \\
\hline$Z$ & 2 \\
\hline$D_{\text {calc }}\left(\mathrm{g} \mathrm{cm}^{-3}\right)$ & 1.981 \\
\hline$F(000)$ & 938 \\
\hline$\mu(\mathrm{Mo}-K \alpha)\left(\mathrm{mm}^{-1}\right)$ & 2.878 \\
\hline$T(\mathrm{~K})$ & 93 \\
\hline Measured $2 \theta$ range $\left(^{\circ}\right)$ & $6.16-54.94$ \\
\hline No. of reflections collected & 12296 \\
\hline Independent reflections & 3598 \\
\hline No. of reflections with $I>2 \sigma(I)$ & 3031 \\
\hline$R(I>2 \sigma(I))^{\mathrm{a}}$ & 0.0349 \\
\hline$R_{\mathrm{w}}$ (all data) ${ }^{\mathrm{b}}$ & 0.0747 \\
\hline
\end{tabular}

Figure 1. Molecular structure of the donor molecule in 1 with the atom-labeling scheme.

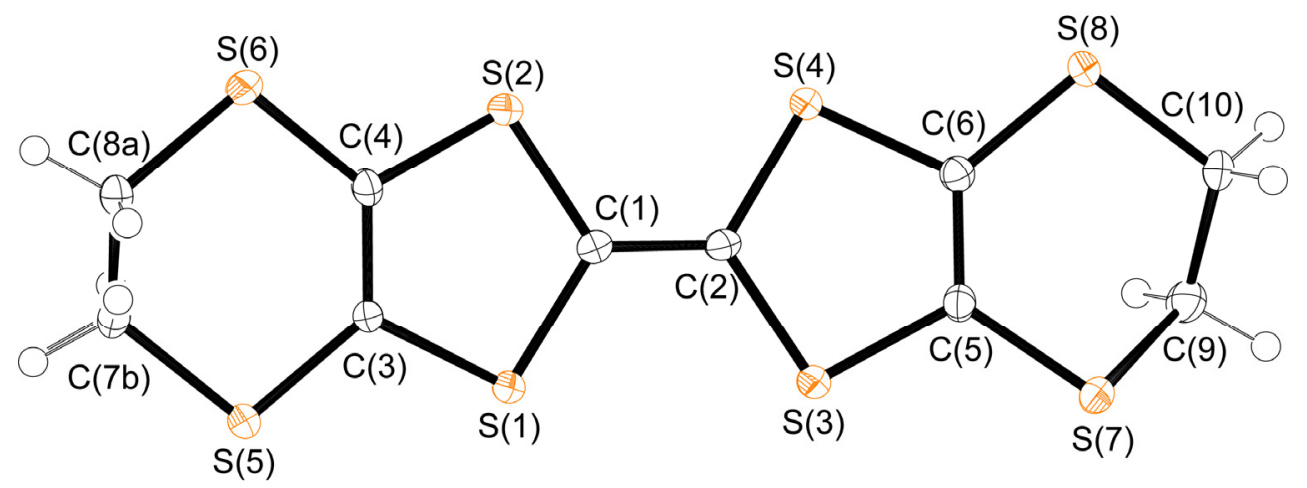


Table 2. Selected bond lengths $(\AA \AA)$ and angles $\left(^{\circ}\right)$ of donor moiety of $\mathbf{1}$.

\begin{tabular}{llll}
\hline Bond & Bond length & Bond & Bond length \\
\hline $\mathrm{C}(1)-\mathrm{C}(2)$ & $1.336(4)$ & $\mathrm{C}(3)-\mathrm{C}(4)$ & $1.351(3)$ \\
$\mathrm{C}(5)-\mathrm{C}(6)$ & $1.353(3)$ & $\mathrm{S}(1)-\mathrm{C}(1)$ & $1.732(3)$ \\
$\mathrm{S}(2)-\mathrm{C}(1)$ & $1.737(2)$ & $\mathrm{S}(3)-\mathrm{C}(2)$ & $1.740(2)$ \\
$\mathrm{S}(4)-\mathrm{C}(2)$ & $1.743(3)$ & $\mathrm{S}(1)-\mathrm{C}(3)$ & $1.755(2)$ \\
$\mathrm{S}(2)-\mathrm{C}(4)$ & $1.753(3)$ & $\mathrm{S}(3)-\mathrm{C}(5)$ & $1.748(3)$ \\
$\mathrm{S}(4)-\mathrm{C}(6)$ & $1.757(3)$ & $\mathrm{S}(5)-\mathrm{C}(3)$ & $1.748(3)$ \\
$\mathrm{S}(6)-\mathrm{C}(4)$ & $1.742(3)$ & $\mathrm{S}(7)-\mathrm{C}(5)$ & $1.742(3)$ \\
$\mathrm{S}(8)-\mathrm{C}(6)$ & $1.743(3)$ & & \\
\hline Bond & Bond angle & Bond & Bond Angle \\
\hline $\mathrm{S}(1)-\mathrm{C}(1)-\mathrm{C}(2)$ & $122.48(19)$ & $\mathrm{S}(2)-\mathrm{C}(1)-\mathrm{C}(2)$ & $122.66(19)$ \\
$\mathrm{S}(3)-\mathrm{C}(2)-\mathrm{C}(1)$ & $123.02(19)$ & $\mathrm{S}(4)-\mathrm{C}(2)-\mathrm{C}(1)$ & $122.19(19)$ \\
$\mathrm{S}(1)-\mathrm{C}(1)-\mathrm{S}(2)$ & $114.84(14)$ & $\mathrm{S}(3)-\mathrm{C}(2)-\mathrm{S}(4)$ & $114.74(14)$ \\
$\mathrm{S}(1)-\mathrm{C}(3)-\mathrm{C}(4)$ & $116.50(19)$ & $\mathrm{S}(2)-\mathrm{C}(4)-\mathrm{C}(3)$ & $116.75(19)$ \\
$\mathrm{S}(3)-\mathrm{C}(2)-\mathrm{C}(1)$ & $123.02(19)$ & $\mathrm{S}(4)-\mathrm{C}(2)-\mathrm{C}(1)$ & $122.19(19)$ \\
$\mathrm{C}(1)-\mathrm{S}(1)-\mathrm{C}(3)$ & $95.38(12)$ & $\mathrm{C}(1)-\mathrm{S}(2)-\mathrm{C}(4)$ & $95.18(12)$ \\
$\mathrm{C}(2)-\mathrm{S}(3)-\mathrm{C}(5)$ & $94.97(12)$ & $\mathrm{C}(2)-\mathrm{S}(4)-\mathrm{C}(6)$ & $95.31(12)$ \\
$\mathrm{C}(3)-\mathrm{C}(4)-\mathrm{S}(6)$ & $128.6(2)$ & $\mathrm{C}(4)-\mathrm{C}(3)-\mathrm{S}(5)$ & $127.97(19)$ \\
$\mathrm{C}(5)-\mathrm{C}(6)-\mathrm{S}(8)$ & $128.8(2)$ & $\mathrm{C}(6)-\mathrm{C}(5)-\mathrm{S}(7)$ & $125.0(2)$ \\
\hline
\end{tabular}

The charge distribution in BEDT-TTF salts can be roughly estimated by using $\delta=(\mathrm{B}+\mathrm{C})-(\mathrm{A}+\mathrm{D})$, where $\mathrm{A}, \mathrm{B}, \mathrm{C}$, and D are the lengths of the four bonds in the BEDT-TTF molecules as shown in Scheme 1 [12]. The $\delta$ value of the donor molecule in this salt was estimated from the crystal structure to be 0.799 using distances summarized in Table 2 . The $\delta$ value is consistent with that of BEDT-TTF with a $+1 / 2$ charge.

Scheme 1. Positions of bonds for the calculation of $\delta$ value of the BEDT-TTF molecules.<smiles>BC1SC2=C(SCCS2)S1=c1sc2c(s1)SCCS2</smiles>

The anion moiety is a mixture of linear $\left[\mathrm{Cu} X_{2}\right]^{-}(X=\mathrm{Br}, \mathrm{Cl})$. Each copper ion occupies the same position on an inversion center. Bromine and chlorine atoms are bonded with copper ions along the same direction. Occupancy ratio between bromine and chlorine is 4:6 in this crystal. $\mathrm{The} \mathrm{Cu}-\mathrm{Br}$ and $\mathrm{Cu}-\mathrm{Cl}$ bond lengths are 2.202 and $2.056 \AA$, respectively. The $\mathrm{Cu}-\mathrm{X}$ separations indicate a $\mathrm{Cu}(\mathrm{I})$ oxidation state (c.f., $2.226 \AA$ in $(\mathrm{TBA}) \mathrm{CuBr}_{2}(\mathrm{Cu}(\mathrm{I})), 2.40 \AA$ in $\mathrm{CuBr}_{2}(\mathrm{Cu}(\mathrm{II})), 2.107 \AA$ in (TBA) $\mathrm{CuCl}_{2}(\mathrm{Cu}(\mathrm{I})), 2.290 \AA$ in $\left.\mathrm{CuCl}_{2} \cdot 2 \mathrm{H}_{2} \mathrm{O}(\mathrm{Cu}(\mathrm{II}))\right)$ [13-15]. $\mathrm{Cu}(\mathrm{I})$ ions should form upon reduction of $\mathrm{Cu}^{\mathrm{II}}$ with BEDT-TTF during the reaction, as reported in [12], meaning two BEDT-TTF molecules must have a total valence of +1 . Thus, the $\delta$ value calculated above is consistent with a $\mathrm{Cu}(\mathrm{I})$ ion. 


\subsection{Crystal Structure of $\mathbf{1}$}

A packing diagram of the salt is shown in Figure 2. The structure is similar to those of $\alpha^{\prime}$-[BEDT-TTF $]_{2}(X)$, where $X=\mathrm{CuCl}_{2}{ }^{-}, \mathrm{AuBr}_{2}{ }^{-}, \mathrm{Ag}(\mathrm{CN})_{2}{ }^{-}$, and $\mathrm{Au}(\mathrm{CN})_{2}{ }^{-}[10,11,16]$. As shown with other $\alpha^{\prime}$-phase salts, the crystallographically equivalent molecules are stacked in pairs along the $a$ axis with a large number of intermolecular $\mathrm{S} \cdots \mathrm{S}$ contacts $(3.366-3.580 \AA)$, which are shorter than van der Waals distance $(3.7 \AA)$. The donors form twisted dimers in the columns through the contacts (3.559-3.580 $\AA$ ) with a torsion angle around the central $\mathrm{C}=\mathrm{C}$ bonds of $33.61^{\circ}$. The closest interdimer $\mathrm{S} \cdots \mathrm{S}$ distance is $3.852 \AA$ along the stacking direction. The linear $\mathrm{Cu} X_{2}(X=\mathrm{Br}$ and $\mathrm{Cl})$ anions are packed into the cavities between the terminal ethylene hydrogen atoms of the BEDT-TTF stacks. In this packing motif, the chlorine atoms of $\alpha^{\prime}$-[BEDT-TTF $]_{2}\left(\mathrm{CuCl}_{2}\right)$ have been partially substituted with bromine atoms [11].

Figure 2. Packing diagrams of $\mathbf{1}$ along (a) $b$ and (b) $a$ axes.

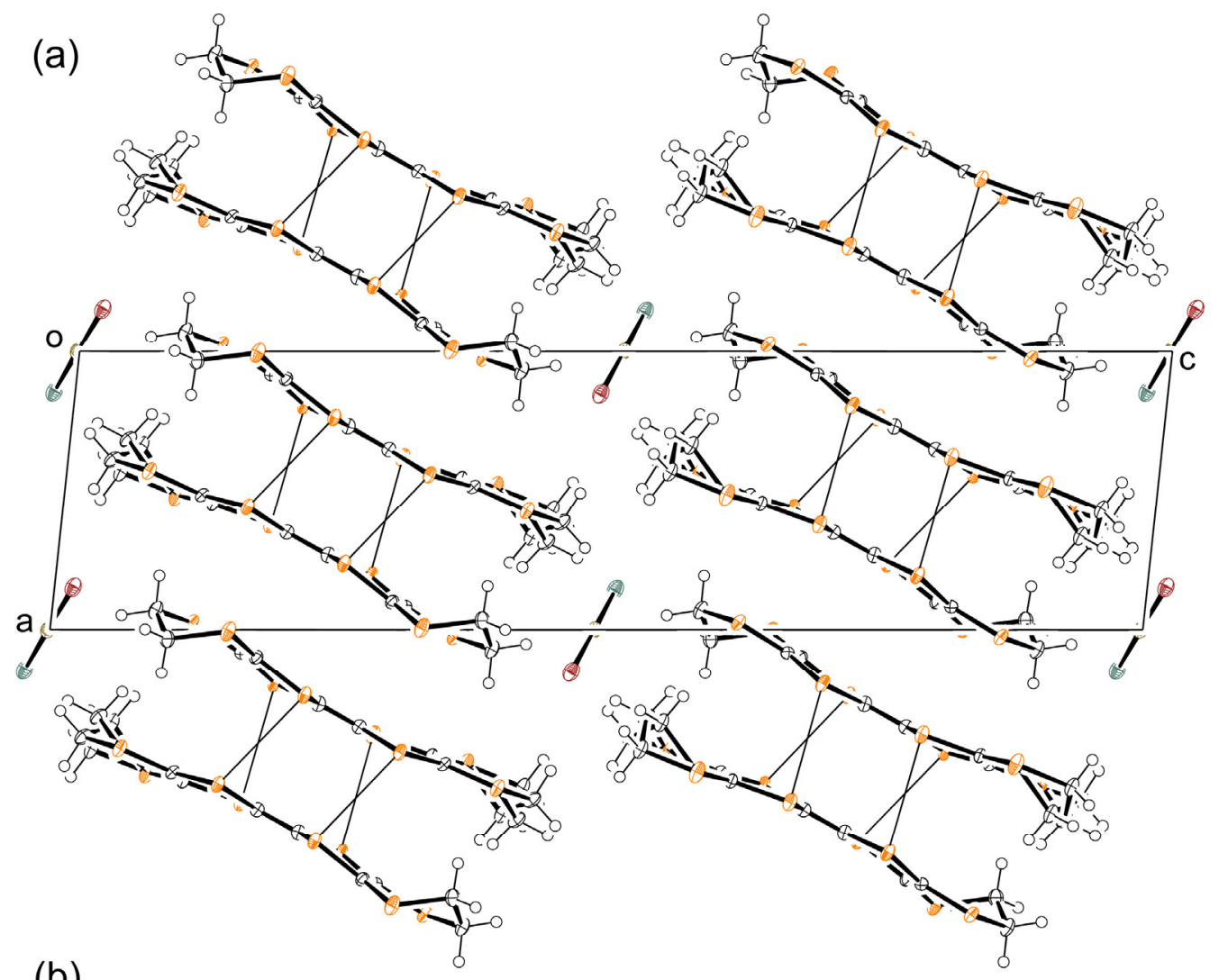

(b)

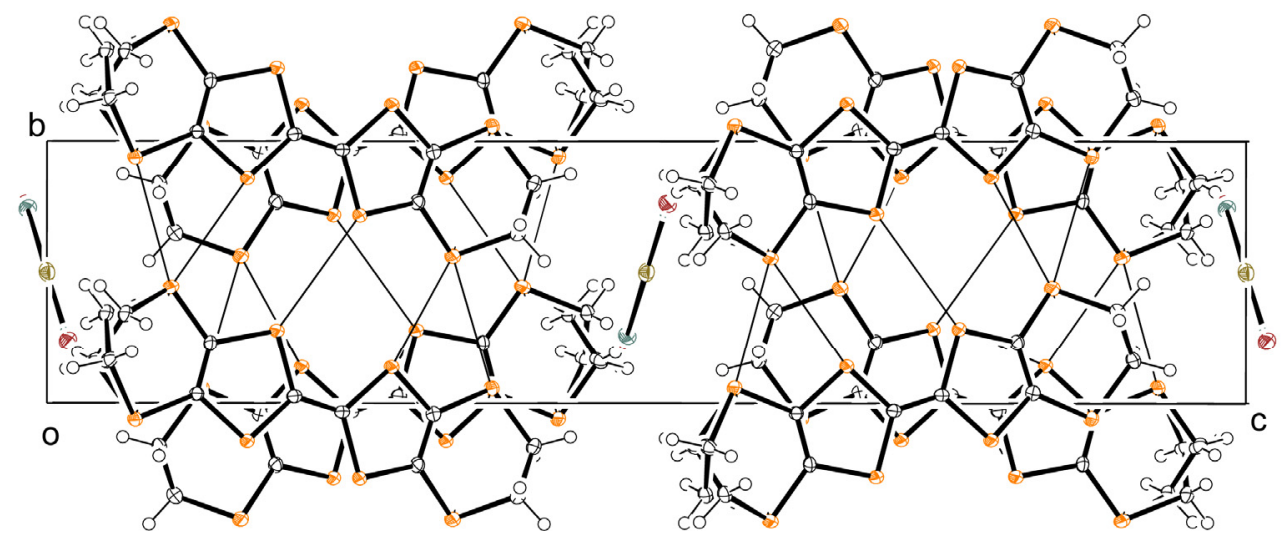




\subsection{Calculated Band Structure of $\mathbf{1}$}

Molecular orbitals of the donor molecules were calculated by using an extended Hückel method. As with other BEDT-TTF salts, calculated HOMOs of BEDT-TTF are characterized by the same signs on each sulfur atom [1,17-19]. Calculated overlap integrals $(S)$ between the HOMOs are listed in Table 3 with a schematic drawing of the donor arrangement. Figure 3 shows the calculated energy bands formed from the HOMOs. Weak dimerization is evident in the salt; one of the face-to-face interactions (a1) is slightly stronger than the other (a2). The crystal has a quasi-one-dimensional character (Figure 3); the face-to-face interactions (a1 and a2) are larger than the side-by-side interactions (b1-b3). Degree of dimerization in the salt is slightly weaker than that in $\alpha^{\prime}-[\mathrm{BEDT}-\mathrm{TTF}]_{2}\left(\mathrm{AuBr}_{2}\right)$ [9]. The dimerization causes a gap between the two upper and lower bands, which correspond to the antibonding and bonding states of the dimer, respectively. The bands of the salt are much wider than the separation between the bands such that the upper band crosses the Fermi level along the wavevector directions $\Gamma \rightarrow \mathrm{X}$ and $\Gamma \rightarrow \mathrm{M}$, but not along $\Gamma \rightarrow \mathrm{Y}$ (Figure 3 ). Thus, the salt is expected to be a quasi-one dimensional metal, and the electrical conductivities should be much greater along the stacking direction (the $a$ axis) than they are along the interstack direction (the $b$ axis). However, the $\mathrm{b} 2$ and $\mathrm{b} 3$ interactions contribute to a distortion of the Fermi surface and to destruction of the perfect nesting, but the magnitudes of these interactions are small; hence the good nesting accounts for the insulating property of the salt. It is well-established that quasi-one dimensional metals can undergo a metal-insulator phase transition, such as Peierls distortion or spin density wave (SDW) formation [20].

Table 3. Overlap integrals $\left(\times 10^{3}\right)$ between the HOMOs of the BEDT-TTF with a schematic diagram of the donor arrangement in the salt.

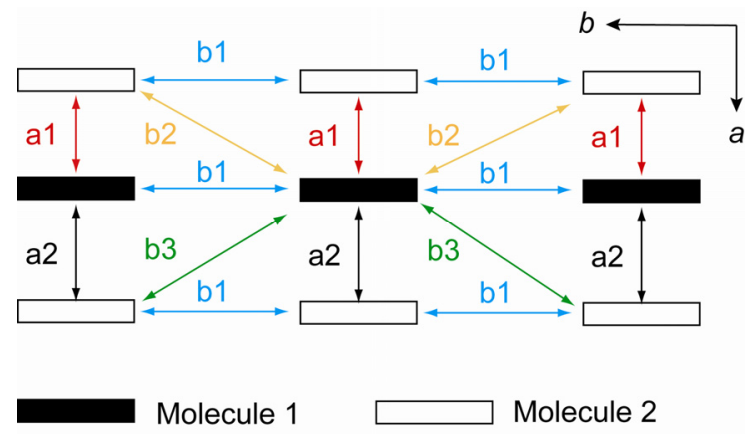

\begin{tabular}{cccc}
\hline Interaction & $\boldsymbol{S}$ & Interaction & $\boldsymbol{S}$ \\
a1 & -13.1 & $\mathrm{~b} 1$ & 1.6 \\
$\mathrm{a} 2$ & -8.1 & $\mathrm{~b} 2$ & -0.33 \\
& & $\mathrm{~b} 3$ & -0.73 \\
\hline
\end{tabular}


Figure 3. Calculated energy band structure and Fermi surface of $\mathbf{1}$.

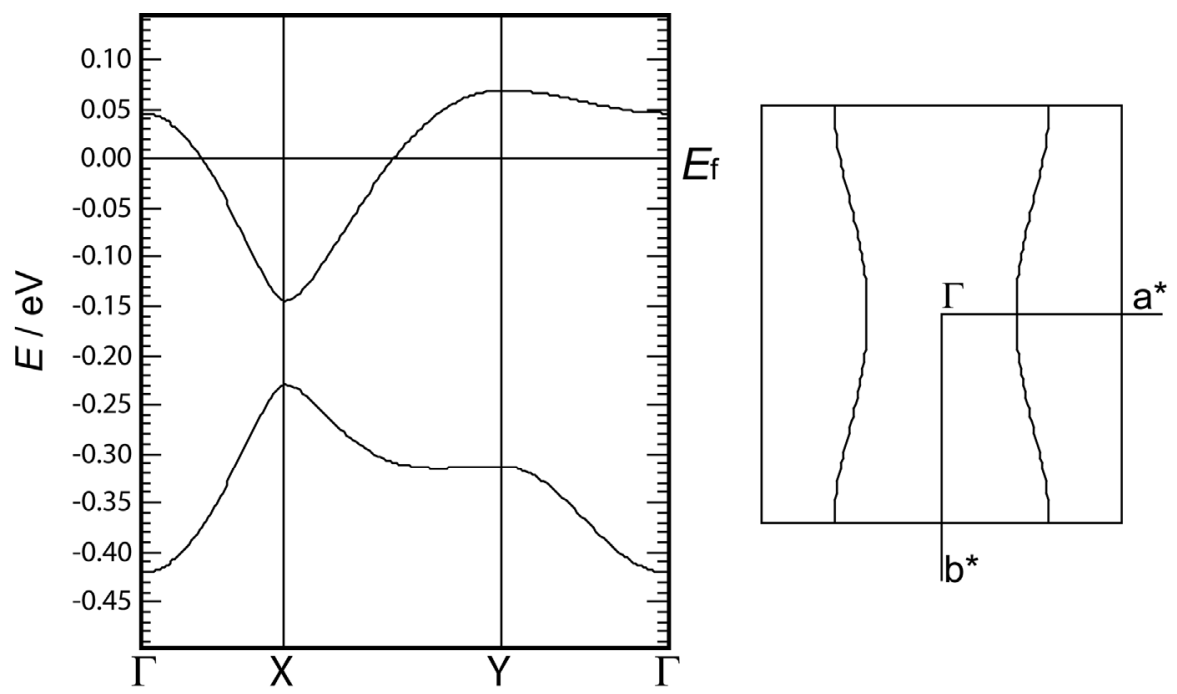

\subsection{Electrical Resistivity of $\mathbf{1}$}

Temperature dependence of resistivity for 1 was measured by using a standard four-probe method in the temperature range of $300-270 \mathrm{~K}$ under ambient pressure. 1 is a semiconductor $\left(\rho_{\mathrm{rt}}=2 \times 10^{2} \Omega\right.$ $\left.\mathrm{cm}, E_{\mathrm{a}}=0.2 \mathrm{eV}\right)$. This conducting behavior is on the same order of magnitude as that of $\alpha^{\prime}$-[BEDT-TTF $]_{2}\left(\mathrm{CuCl}_{2}\right)$, which has the same donor arrangement. Magnetic measurements on the salt are necessary in order to investigate electronic structure of the salt. However, since the yield of the salt is very low, we could not obtain enough of the salt for the magnetic measurements. Thus, we estimated the electronic state by using the symmetry number $(\eta)$. Mori has proposed that the following equation for $\eta$ can be used to describe the magnetic state of the insulating phase of BEDT-TTF radical cation salts: $\eta=$ (Number of molecules in a unit cell) $\times$ (Number of crystallographically independent molecules) [9]. $\eta$ for 1 was determined to be 4 , considering the donor layer. This value is similar to that of other $\alpha^{\prime}$-phase salts, indicating that $\alpha^{\prime}$-phase salts are paramagnetic insulators. $\alpha^{\prime}$-[BEDT-TTF] ${ }_{2} X$ salts $\left(X=\mathrm{AuBr}_{2}{ }^{-}, \mathrm{CuCl}_{2}{ }^{-}, \mathrm{Ag}(\mathrm{CN})_{2}{ }^{-}\right)$have highly localized spin systems $(S=1 / 2$ per dimer) with strong intrasite coulomb repulsion (high $-U$ limit). These salts exhibit a paramagnetic susceptibility with antiferromagnetic transitions in the range of 50-60 K [12]. Thus, these salts are paramagnetic Mott-Hubbard insulators. On the basis of the $\eta$ value and the electronic systems of $\alpha^{\prime}$-[BEDT-TTF] $]_{2} X$ $\left(X=\mathrm{AuBr}_{2}{ }^{-}, \mathrm{CuCl}_{2}{ }^{-}, \mathrm{Ag}(\mathrm{CN})_{2}{ }^{-}\right)$, the ground state of $\mathbf{1}$ is a paramagnetic Mott-Hubbard insulating state due to the half-filled band with strong electron correlation.

\section{Experimental Section}

\subsection{Materials}

BEDT-TTF (Tokyo Chemical Industry Co., Ltd.), $\mathrm{CuBr}_{2}$, and $\mathrm{CuCl}_{2}$ (Wako Pure Chemical Industries Ltd.) are commercially available regents. Tetrahydrofuran (THF) and methanol $(\mathrm{MeOH})$ (Wako Pure Chemicals Co. Ltd.) were used without further purification. 


\subsection{Preparation of $\alpha^{\prime}-[B E S T-T T F]_{2}\left(C u B r_{2}\right)_{0.4}\left(\mathrm{CuCl}_{2}\right)_{0.6}$}

Cation radical salt $\alpha^{\prime}$-[BEDT-TTF $]_{2}\left(\mathrm{CuBr}_{2}\right)_{0.4}\left(\mathrm{CuCl}_{2}\right)_{0.6}$ was prepared by diffusion a THF solution $(10 \mathrm{~mL})$ solution of BEDT-TTF $(15 \mathrm{mg}, 0.039 \mathrm{mmol})$ as a donor, a mixture of THF and $\mathrm{MeOH}$ $(10 \mathrm{~mL}, v / v=1: 1)$ as a mediating layer, and a $\mathrm{MeOH}$ solution $(10 \mathrm{~mL})$ of $\mathrm{CuBr}_{2}(45 \mathrm{mg}, 0.2 \mathrm{mmol})$ and $\mathrm{CuCl}_{2}(108 \mathrm{mg}, 0.8 \mathrm{mmol})$ as an oxidant for a week at room temperature (Yield: $\left.0.5 \%\right)$. The chemical formula of the salt was determined by X-ray crystallographic analysis.

\subsection{Crystal Structure Determination}

Diffraction data of 1 were collected at $93 \mathrm{~K}$ under a cold nitrogen gas stream on a Rigaku AFC 10 diffractometer equipped with a Saturn 724 CCD detector with a graphite-monochromated Mo $K \alpha$ radiation $\left(\lambda=0.71073 \AA\right.$ ). The intensity data were measured at $0.5^{\circ}$ intervals of $\omega$. Bragg spots were integrated using the CrystalClear program package, and corrections for Lorentz polarization effects and absorption were performed. The structure was solved by using direct methods (SIR 97) and refined by using full-matrix least squares analysis (SHELXL 97) on $F^{2}$ [21,22]. All non-hydrogen atoms were refined anisotropically. The hydrogen atoms were added at calculated positions and refined by applying riding models. The structure of the anionic moiety was solved by restraint method as two anions, $\mathrm{CuBr}_{2}{ }^{-}$and $\mathrm{CuCl}_{2}{ }^{-}$, occupied almost same positions. The occupancies of the anionic molecules were refinement under the restraint. The crystallographic data for $\mathbf{1}$ are summarized in Table 1.

\subsection{Overlap Integral Calculation}

Intermolecular overlap integrals $(S)$ between the HOMOs of the donor were calculated by using an extended Hückel molecular orbital (MO) method. Semi-empirical parameters for the Slater-type atomic orbitals were taken from the literature [23-25].

\subsection{Electrical Resistivity}

Temperature dependence of the electrical resistivity was measured by using a standard four-probe method in the temperature range of 300-270 K at ambient pressure for 1 . The data were collected on a Quantum Design PPMS system. Gold wires (15 $\mu \mathrm{m}$ diameter) were attached to the crystal with carbon paste.

\section{Conclusions}

A new BEDT-TTF radical cation salt with mixed anions, $\alpha^{\prime}-[\mathrm{BEDT}-\mathrm{TTF}]_{2}\left(\mathrm{CuBr}_{2}\right)_{0.4}\left(\mathrm{CuCl}_{2}\right)_{0.6}$, was obtained by diffusion of solutions containing neutral BEDT-TTF and $\mathrm{Cu} X_{2}(X=\mathrm{Br}$ or $\mathrm{Cl})$. This salt is the first example of an $\alpha^{\prime}$-phase BEDT-TTF radical cation salt. The conducting behavior and calculated band structure suggests that the salt may be a paramagnetic Mott-Hubbard insulator with strong electron correlation in the ground state. Although the band filling is similar to that of $\alpha^{\prime}$-[BEDT-TTF $]_{2}\left(\mathrm{CuCl}_{2}\right)$, our preparation method can be used to obtain new BEDT-TTF radical cation salts with various anions and interesting band fillings. 


\section{Acknowledgments}

We thank Reizo Kato (RIKEN, Japan) for the energy band calculations and Takeo Fukunaga (Tokyo University of Science) for the crystallographic analysis.

\section{Conflict of Interest}

The authors declare no conflict of interest.

\section{References}

1. Shibaeva, R.P.; Yagubskii, E.B. Molecular conductors and superconductors based on trihalides of BEDT-TTF and some of its analogues. Chem. Rev. 2004, 104, 5347-5378.

2. Taniguchi, H.; Miyashita, M.; Uchiyama, K.; Satoh, K.; Môri, N.; Okamoto, H.; Miyagawa, K.; Kanoda, K.; Hedo, M.; Uwatoko, Y. Superconductivity at $14.2 \mathrm{~K}$ in Layered Organics under Extreme Pressure. J. Phys. Soc. Jpn. 2003, 72, 468-471.

3. Kini, A.M.; Geiser, U.; Wang, H.H.; Carlson, K.D.; Williams, J.M.; Kwok, W.K.; Vandervoort, K.G.; Thompson, J.E.; Stupka, D.L.; Jung, D.; et al. A new ambient-pressure organic superconductor, $\kappa-(\mathrm{ET})_{2} \mathrm{Cu}\left[\mathrm{N}(\mathrm{CN})_{2}\right] \mathrm{Br}$, with the highest transition temperature yet observed (inductive onset $T_{\mathrm{c}}=11.6 \mathrm{~K}$, resistive onset $=12.5 \mathrm{~K}$ ). Inorg. Chem. 1990, 29, 2555-2557.

4. Williams, J.M.; Kini, A.M.; Wang, H.H.; Carlson, K.D.; Geiser, U.; Montgomery, L.K.; Pyrka, G.J.; Watkins, D.M.; Kommers, J.M.; Boryschuk, S.J.; et al. From semiconductor-semiconductor transition $(42 \mathrm{~K})$ to the highest-Tc organic superconductor, $\kappa-(\mathrm{ET})_{2} \mathrm{Cu}\left[\mathrm{N}(\mathrm{CN})_{2}\right] \mathrm{Cl}\left(T_{\mathrm{c}}=12.5 \mathrm{~K}\right)$. Inorg. Chem. 1990, 29, 3272-3274.

5. Posselt, H.; Müller, H.; Andres, K.; Sushko, Y.V.; Saito, G. Reentrant meissner effect in the organic superconductor $\kappa-\mathrm{ET}_{2} \mathrm{Cu}\left[\mathrm{N}(\mathrm{CN})_{2}\right] \mathrm{Cl}_{1-x} \mathrm{Br}_{x}$ under pressure. Synth. Met. 1995, 70, 917-918.

6. Ishiguro, T.; Ito, H.; Yamauchi, Y.; Ohmichi, E.; Kubota, M.; Yamochi, H.; Saito, G.; Kartsovnik, M.V.; Tanatar, M.A.; Sushko, U.V.; et al. Electronic phase diagrams and fermi surfaces of $\kappa$-(ET) $)_{2} X$, the high $T_{\mathrm{c}}$ organic superconductors. Synth. Met. 1997, 85, 1471-1478.

7. Mori, H.; Okano, T.; Tanaka, S.; Tamura, M.; Nishio, Y.; Kajita, K.; Mori, T. Discontinuous Change of Metal-Insulator Transition in the Alloyed $\theta$-system: $\theta$-(BEDT-TTF $)_{2}\left(\mathrm{Rb}_{1-x} \mathrm{Cs}_{x}\right) \mathrm{Zn}(\mathrm{SCN})_{4}$. J. Phys. Soc. Jpn. 2000, 69, 1751-1756.

8. Kato, R.; Kobayashi, H.; Kobayashi, A.; Nishio, Y.; Kajita, K.; Sasaki, W. "Partially" superconducting behavior of $\theta-(\mathrm{BEDT}-\mathrm{TTF})_{2}\left(\mathrm{I}_{3}\right)_{1-x}(\mathrm{~A})_{x}\left(\mathrm{~A}=\mathrm{AuI}_{2}, \mathrm{I}_{2} \mathrm{Br}\right)$ system. Chem. Lett. 1986, 6, 957-960.

9. Mori, T. Structural genealogy of BEDT-TTF-based organic conductors III. Twisted molecules: $\delta$ and $\alpha^{\prime}$ phases. Bull. Chem. Soc. Jpn. 1999, 72, 2011-2027.

10. Beno, M.A.; Firestone, M.A.; Leung, P.C.W.; Sowa, L.M.; Wang, H.H.; Williams, J.M.; Whangbo, M.-H. Crystal and band electronic structures of a new class of 2:1 organic conducting salts $\alpha^{\prime}-(\mathrm{BEDT}-\mathrm{TTF})_{2} X, X^{-}=\mathrm{Ag}(\mathrm{CN})_{2}{ }^{-}, \mathrm{Au}(\mathrm{CN})_{2}{ }^{-}$and $\mathrm{AuBr}_{2}{ }^{-}$. Solid State Commun. 1986, 57, 735-739.

11. Kurmoo, M.; Talham, D.R.; Day, P.; Howard, J.A.K.; Stringer, A.M.; Obertelli, D.S.; Friend, R.H. (BEDT-TTF $)_{2} \mathrm{CuCl}_{2}$, a new conducting charge transfer salt. Synth. Met. 1988, 22, 415-418. 
12. Guionneau, P.; Kepert, C.J.; Bravic, G.; Chasseau, D.; Truter, M.R.; Kurmoo, M.; Day, P. Determining the charge distribution in BEDT-TTF salts. Synth. Met. 1997, 86, 1973-1974.

13. Asplund, M.; Jagner, S.; Nilsson, M. Crystal structures of tetrabutylammonium dichlorocuprate(I)

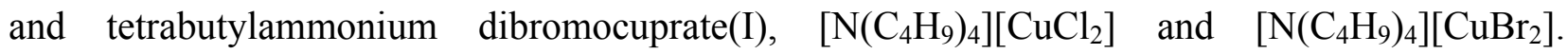
Acta Chem. Scand. 1983, A37, 57-62.

14. Enberg, A. An X-ray refinement of the crystal structure of copper(II) chloride dihydrate. Acta Chem. Scand. 1970, 24, 3510-3520.

15. Helmholz, L. The crystal structure of anhydrous cupric bromide. J. Am. Chem. Soc. 1947, 69, 886-889.

16. Obertelli, S.D.; Friend, R.H.; Talham, D.R.; Kurmoo, M.; Day, P. The magnetic susceptibility and EPR of the organic conductors $\alpha$-(BEDT-TTF $)_{2} X, X=\mathrm{AuBr}_{2}, \mathrm{CuCl}_{2}$ and $\mathrm{Ag}(\mathrm{CN})_{2}$. J. Phys. Condens. Matter 1989, 1, 5671-5680.

17. Horiuchi, S.; Yamochi, H.; Saito, G.; Sakaguchi, K.; Kusunoki, M. Nature and origin of stable metallic state in organic charge-transfer complexes of bis(ethylenedioxy)tetrathiafulvalene. J. Am. Chem. Soc. 1996, 118, 8604-8622.

18. Mori, T.; Kobayashi, A.; Sasaki, Y.; Kobayashi, H.; Saito, G.; Inokuchi, H. The intermolecular interaction of tetrathiafulvalene and bis(ethylenedithio)tetrathiafulvalene in organic metals. calculation of orbital overlaps and models of energy-band structures. Bull. Chem. Soc. Jpn. 1984, $57,627-633$.

19. Kobayashi, H.; Kato, R.; Mori, T.; Kobayashi, A.; Sasaki, Y.; Saito, G.; Inokuchi, H. Organic conductors based on multi-sulfur $\pi$-donor and/or $\pi$-acceptor molecules-BEDT-TTF, BMDT-TTF, BPDT-TTF, and M(dmit $)_{2}{ }^{-}$. Mol. Cryst. Liq. Cryst. 1985, 125, 125-134.

20. Miller, J.S. Extended Linear Chain Compounds; Plenum Press: New York, NY, USA, 1983; Volumes 1-3.

21. Altomare, A.; Burla, M.C.; Gamalli, M.; Cascarano, M.; Giacovazzo, G.L.; Guagliardi, A.; Moliterni, A. SIR97: A new tool for crystal structure determination and refinement. J. Appl. Crystallogr. 1999, 32, 115-119.

22. Sheldrick, G.M. A short history of SHELX. Acta Crystallogr. Sect. A 2008, 64, 112-122.

23. Summerville, R.H.; Hoffmann, R. Tetrahedral and other $\mathrm{M}_{2} \mathrm{~L}_{6}$ transition metal dimers. J. Am. Chem. Soc. 1976, 98, 7240-7254.

24. Joergensen, K.A.; Hoffmann, R. Binding of alkenes to the ligands in $\mathrm{OsO}_{2} X_{2}(X=\mathrm{O}$ and NR) and $\mathrm{CpCo}(\mathrm{NO})_{2}$. A frontier orbital study of the formation of intermediates in the transition-metal-catalyzed synthesis of diols, amino alcohols, and diamines. J. Am. Chem. Soc. 1986, 108, 1867-1876.

25. Schilling, B.E.R.; Hoffmann, R.; Faller, J.W. Effect of ligand asymmetry on the structure and reactivity of $\mathrm{CpMLL}^{\prime}(\mathrm{allyl})(\mathrm{Cp}=$ cyclopentadienyl, $\mathrm{M}=$ metal, $\mathrm{L}=$ ligand) and -(ethylene) complexes. J. Am. Chem. Soc. 1979, 101, 592-598.

(C) 2012 by the authors; licensee MDPI, Basel, Switzerland. This article is an open access article distributed under the terms and conditions of the Creative Commons Attribution license (http://creativecommons.org/licenses/by/3.0/). 